\title{
Role of Wind Filtering and Unbalanced Flow Generation in Middle Atmosphere Gravity Wave Activity at Chatanika Alaska
}

\author{
Colin C. Triplett ${ }^{1,2}$, Richard L. Collins ${ }^{1,2, *}$, Kim Nielsen $^{3}$, V. Lynn Harvey ${ }^{4}$ and \\ Kohei Mizutani ${ }^{5}$ \\ 1 Geophysical Institute, University of Alaska Fairbanks, Fairbanks, AK 99775, USA; cctriplett2@alaska.edu \\ 2 Department of Atmospheric Sciences, University of Alaska Fairbanks, Fairbanks, AK 99775, USA \\ 3 Department of Physics, Utah Valley University, Orem, UT 84805, USA; Kim.Nielsen@uvu.edu \\ 4 Laboratory for Atmospheric and Space Physics, University of Colorado, Boulder, CO 80303, USA; \\ harvey@lasp.colorado.edu \\ 5 Applied Electromagnetic Research Institute, National Institute of Information and Communications \\ Technology, Koganei, Tokyo 184-8795, Japan; mizutani@nict.go.jp \\ * Correspondence: rlcollins@alaska.edu; Tel.: +1-907-474-7607
}

Academic Editor: Vanda Grubišić

Received: 31 October 2016; Accepted: 20 December 2016; Published: 26 January 2017

\begin{abstract}
The meteorological control of gravity wave activity through filtering by winds and generation by spontaneous adjustment of unbalanced flows is investigated. This investigation is based on a new analysis of Rayleigh LiDAR measurements of gravity wave activity in the upper stratosphere-lower mesosphere (USLM, 40-50 km) on 152 nights at Poker Flat Research Range (PFRR), Chatanika, Alaska $\left(65^{\circ} \mathrm{N}, 147^{\circ} \mathrm{W}\right)$, over 13 years between 1998 and 2014. The LiDAR measurements resolve inertia-gravity waves with observed periods between $1 \mathrm{~h}$ and $4 \mathrm{~h}$ and vertical wavelengths between $2 \mathrm{~km}$ and $10 \mathrm{~km}$. The meteorological conditions are defined by reanalysis data from the Modern-Era Retrospective Analysis for Research and Applications (MERRA). The gravity wave activity shows large night-to-night variability, but a clear annual cycle with a maximum in winter, and systematic interannual variability associated with stratospheric sudden warming events. The USLM gravity wave activity is correlated with the MERRA winds and is controlled by the winds in the lower stratosphere through filtering by critical layer filtering. The USLM gravity wave activity is also correlated with MERRA unbalanced flow as characterized by the residual of the nonlinear balance equation. This correlation with unbalanced flow only appears when the wind conditions are taken into account, indicating that wind filtering is the primary control of the gravity wave activity.
\end{abstract}

Keywords: gravity wave generation; gravity wave propagation; critical layer filtering; ageostrophic adjustment; stratospheric sudden warming (SSW); Rayleigh LiDAR

\section{Introduction}

Gravity waves are an essential component of the atmospheric circulation [1-3]. How these waves affect the circulation of the stratosphere is a focus of the Stratospheric Processes and their Role in Climate (SPARC) program [4] and the recent Deep Propagating Gravity Wave Experiment (DEEPWAVE) campaign [5]. Gravity wave sources include orographic generation, convection and meteorological conditions, including wind shears, ageostrophic adjustment and wave-wave interaction [3]. The Arctic wintertime middle atmosphere provides a natural laboratory for understanding the role of gravity waves in the general circulation. When the middle atmosphere is disturbed during a stratospheric sudden warming (SSW) event, breaking planetary waves reverse the circulation resulting in filtering of orographic gravity waves, while non-orographic waves propagate 
into the mesosphere and contribute to the recovery of the circulation (e.g., [6-10]). During these events, there is significant ageostrophic imbalance in the flows as the tropospheric and stratospheric jets depart from geostrophic balance. The generation of gravity waves by adjustment of an ageostrophic flow returning to the lower geostrophic state and radiating the excess energy as gravity waves has long been recognized [11-13]. More recent studies of gravity waves have studied the generation of gravity waves through spontaneous adjustment of unbalanced flows that include the contributions of mesoscale phenomena, such as jets and fronts [14]. In the absence of convection during the winter, unbalanced flows (associated with ageostrophic flows, jets and fronts) are expected to be a significant source of gravity waves [15-17].

We present an analysis of Rayleigh LiDAR measurements of gravity wave activity on 152 nights at Poker Flat Research Range (PFRR), Chatanika, Alaska ( $\left.65^{\circ} \mathrm{N}, 147^{\circ} \mathrm{W}\right)$, over 13 years between 1998 and 2014. Previous Rayleigh LiDAR studies at Chatanika have focused on gravity wave activity measured on 61 nights associated with SSWs over three winters between 2002 and 2005 and two winters during the International Polar Year between 2007 and 2009 [18,19]. In this study, we extend the scope of these earlier studies to investigate the role of both filtering by the winds and generation by spontaneous adjustment of unbalanced flow in determining the gravity wave activity in the Arctic upper stratosphere and lower mesosphere $(40-50 \mathrm{~km})$. Our goal is to look at how the gravity wave activity varies with wind filtering and unbalanced flow over multiple years rather than focus on individual case studies as have been presented previously (e.g., $[16,17])$. This paper is arranged as follows. In Section 2, we describe the Rayleigh LiDAR system at PFRR, the MERRA reanalysis, and the techniques and methods used to determine and characterize gravity wave activity, winds and flow imbalance. In Section 3, we first give an overview of the Rayleigh LiDAR measurements of the gravity wave activity at Chatanika; we than illustrate the relationship between gravity wave activity, wind and unbalanced flows during the major SSW in 2009 and, finally, investigate the correlation between the gravity wave activity and both wind and unbalanced flow in the whole dataset. In Section 4 , we discuss the results in terms of other observations. Finally, in Section 5, we present our conclusions.

\section{Experiments}

\subsection{Rayleigh LiDAR}

The National Institute of Information and Communications (NICT) Rayleigh LiDAR has been operated at Poker Flat Research Range, Chatanika, Alaska, since 1997. Earlier studies of gravity waves at Chatanika have focused on single observations [20], observations over several winters [18,19] or observations associated with mesospheric inversion layers [21]. Here, we draw on observations made on 327 nights under clear sky conditions between 14 November 1997 and 10 April 2014. We limit our attention to the highest quality observations that meet the following criteria: the duration of the observation is greater than five hours; there are no gaps in the observation of more than $30 \mathrm{~min}$; and the LiDAR signal does not change by more than $50 \%$ between successive raw LiDAR profiles. We found that 152 nighttime observations satisfied these criteria between 11 March 1998 and 10 April 2014. These observations, which varied in duration between $5.2 \mathrm{~h}$ and $15.4 \mathrm{~h}$, had an average duration of $9.0 \mathrm{~h}$. Of these 152 observations, 81 observations (or 53\%) were made during December-January-February (DJF); 46 observations (or 32\%) were made during March-April-May (MAM); only two observations (or 1\%) were made in June-July-August (JJA); and 23 (or 15\%) were made during September-October-November (SON). We plot the monthly distribution of observations in Figure 1. The seasonal distribution of observations reflects both the skylight conditions (where observations are made after nautical twilight (i.e., $-12^{\circ}$ solar declination)) and the cloudiness at Chatanika (where March is the least cloudy month). There are no LiDAR observations that satisfy our data quality criteria made during the months of May, June and July due to the short and bright nights at this high latitude site. 


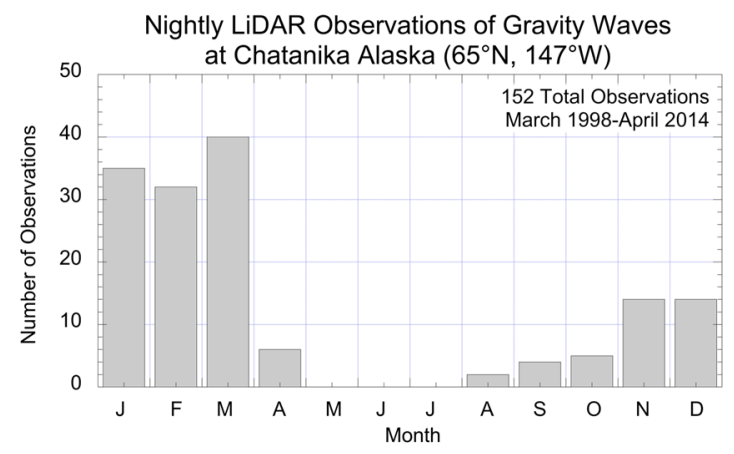

Figure 1. Histogram by month of Rayleigh LiDAR observations at Chatanika, Alaska, between March 1998 and April 2014.

We use the same methods for the retrieval of density and temperature profiles from raw LiDAR signal profiles as in earlier studies at Chatanika (e.g., [19]) to characterize the gravity wave activity in the upper stratosphere-lower mesosphere (USLM). In summary, we determine the relative density fluctuations from the sequence of 30-min density profiles that are successively offset by $5 \mathrm{~min}$. We determine the buoyancy frequency from the average temperature profile. We use an initial temperature at $80 \mathrm{~km}$ from the SPARC atlas [22,23]. We remove fluctuations with periods longer than $4 \mathrm{~h}$ from the density fluctuations. The removal of low-frequency fluctuations has important implications for the values of the potential energy. Without this high-pass filtering, the fluctuations would include contributions from waves with periods up to the length of the observation period and so include contributions from tides. We find that the inclusion of periods longer than $4 \mathrm{~h}$ increases the specific potential energies by a factor of between 1.3 and 13 , with an average value of 4.5 . We determine the average mean square fluctuations over the given altitude (i.e., $40-50 \mathrm{~km}$ ), the average buoyancy period over the same altitude range and then determine the corresponding RMS displacement and specific potential energy (energy per unit mass) using established relationships (e.g., [18,19,24]). Thus, these Rayleigh LiDAR measurements document inertia-gravity waves with periods between $1 \mathrm{~h}$ and $4 \mathrm{~h}$ and vertical wavelengths between $2 \mathrm{~km}$ and $10 \mathrm{~km}$.

\subsection{Meteorological Reanalysis}

The Modern-Era Retrospective Analysis for Research and Applications (MERRA) reanalysis dataset describes the meteorological conditions in the troposphere, stratosphere and lower-mesosphere since 1980 [25]. We use MERRA to study the relationships between the gravity wave activity and the mean winds and the ageostrophy. For this study, we use the Data Assimilation System 3d analyzed state on pressure (inst6_3d_ana_Np) dataset at 0600 Universal Time (UT) corresponding to 2100 Local Standard Time ((LST), LST $=\mathrm{UT}-9 \mathrm{~h})$ to represent the nighttime conditions corresponding to the LiDAR observation. This MERRA dataset has a spatial resolution of $1 / 2^{\circ} \times 2 / 3^{\circ}$ and 40 vertical levels set on constant pressure surfaces. We determined the corresponding geometric altitudes using established techniques [26].

We investigate the correlation between the gravity wave-specific potential energy (energy per unit mass) and the magnitude of the horizontal wind by combining the zonal and meridional components of the wind at each pressure level over Chatanika. We investigate the correlation between the gravity wave-specific potential energy and unbalanced flow as characterized by the residual in the nonlinear balance equation $(\triangle N B E)$ [27-29]. We calculate $\triangle N B E$ using the following equation,

$$
\begin{gathered}
\triangle N B E=2 J(u, v)-\beta u+f \zeta-\nabla^{2} \phi, \\
J(u, v)=\frac{\partial u}{\partial x} \frac{\partial v}{\partial y}-\frac{\partial v}{\partial x} \frac{\partial u}{\partial y},
\end{gathered}
$$


where $u$ and $v$ are the zonal and meridional wind, respectively, and $\phi$ is the geopotential height. $J$ is the Jacobian; $\beta$ is the meridional derivative of the Coriolis parameter; $f$ is the Coriolis parameter; and $\zeta$ is the relative vorticity. Several studies have shown that regions of enhanced $\triangle N B E$ and gravity wave activity are collocated [14]. We validated our implementation by producing both similar meteorological patterns and values of $\triangle N B E$ with MERRA reanalysis corresponding to two published studies [29,30]. To investigate both the local and the regional influence of ageostrophy, we calculate averages of the $\triangle N B E$ at each pressure level over all points locally within an $800-\mathrm{km}$ radius of Chatanika and regionally over the Northern Hemisphere poleward of $50^{\circ} \mathrm{N}$ [17].

In our correlation study, we calculate both the Spearman and Pearson correlation coefficients [31]. The Pearson correlation coefficient represents the traditional linear correlation coefficient. The Spearman correlation coefficient is the correlation based on the rank of the data; it does not require the data to have a normal distribution, and it is less susceptible to outliers [32]. We primarily report the Spearman correlation coefficients.

\section{Results}

\subsection{Rayleigh LiDAR Measurements of Gravity Wave Activity}

We first consider the stability of the USLM and show the buoyancy period averaged over the $40-50-\mathrm{km}$ altitude range as a function of day of year in Figure 2 . The values of the nightly averaged buoyancy period vary between $256 \mathrm{~s}$ and $360 \mathrm{~s}$ with an average of $304 \mathrm{~s}$. The values of the buoyancy period show increasing stability in August, September and October. However, from November to March, there is significantly more variability in the stability, with the largest range of values found in January with values varying between $267 \mathrm{~s}$ and $360 \mathrm{~s}$.

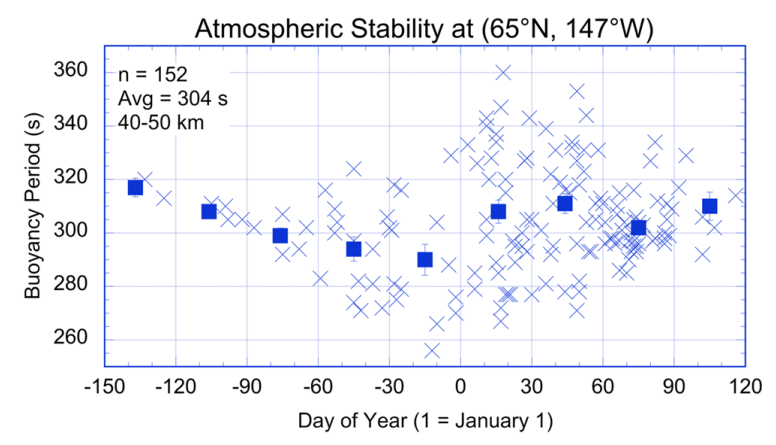

Figure 2. Buoyancy periods measured by Rayleigh LiDAR on 152 nights at Chatanika, Alaska. The data are plotted as the day of year from August to April. The day of year counts from 1 on 1 January, day of year 30 corresponds to 30 January, and day of year -30 corresponds to 1 December. Solid squares represent the monthly average values.

We present the USLM gravity wave activity as a function of day of year in Figure 3. We show both the primary LiDAR measurements of the RMS relative density fluctuations (Figure 3a) and the derived specific potential energy (Figure $3 b$ ). The values of the nightly RMS relative density fluctuations vary between $0.13 \%$ and $1.04 \%$ with an average of $0.40 \%( \pm 0.01 \%)$. The signal-to-noise ratio (SNR) of the measurements varies between 0.27 and 22 with an average value of $4.4( \pm 0.3)$. We also plot the monthly average values with their standard errors. The monthly averages show a wintertime maximum extending from November to January. We show the specific potential energies in Figure $3 \mathrm{~b}$. The values vary between 0.41 and $12 \mathrm{~J} / \mathrm{kg}$ with an average value of $2.6 \mathrm{~J}( \pm 0.2 \mathrm{~J})$. The maximum nightly values in all quantities are found in January and the lowest values in March. The night-to-night variability is greatest in January where the values of the specific potential energy vary by a factor of 29 , reflecting both the variability in the RMS relative density fluctuations and the buoyancy period. The maximum monthly average in both measures of gravity wave activity is found in November, and 
the minimum monthly value is found in August. The maximum in November represents a seasonal maximum in wave activity, as during November, December and January, the monthly mean values of all quantities differ by less than their standard errors.

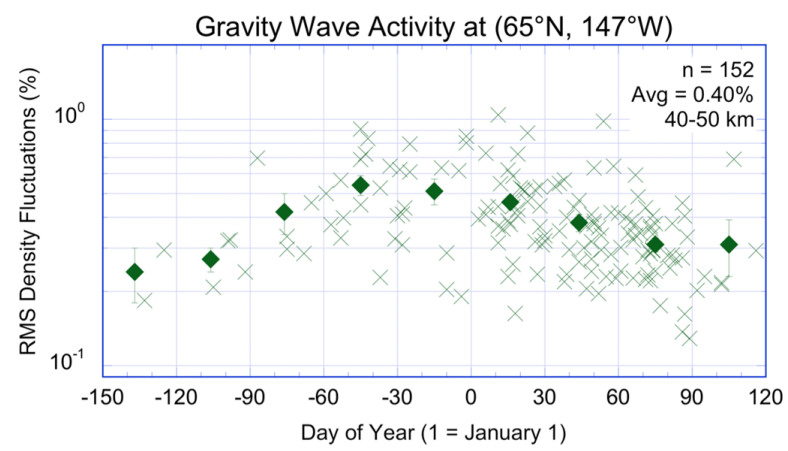

(a)

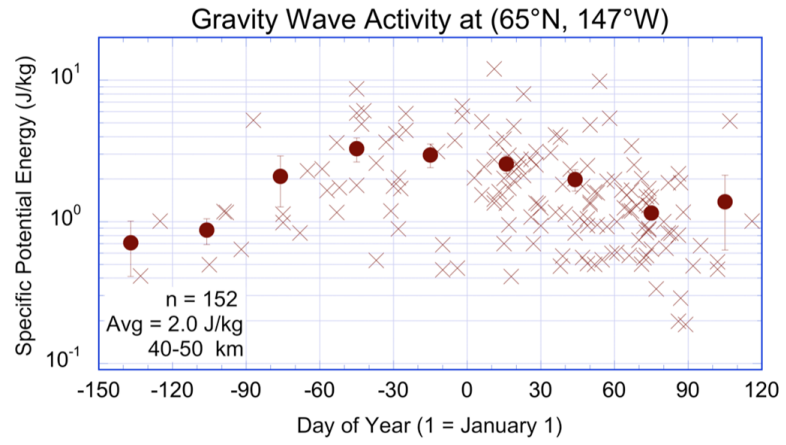

(b)

Figure 3. Gravity wave activity measured by Rayleigh LiDAR on 152 nights at Chatanika, Alaska. The data are plotted as the day of year from August to April. The day of year counts from 1 on 1 January, day of year 30 corresponds to 30 January, and day of year -30 corresponds to 1 December. (a) RMS density fluctuations with monthly average values as solid diamonds; (b) specific potential energies with monthly average values as solid circles.

To better understand how the waves are propagating with altitude, we calculate the specific potential energy over the $40.0-47.5 \mathrm{~km}$ altitude range and the $47.5-55.0 \mathrm{~km}$ altitude range. We limit our attention to those observations that have an SNR greater than one in the $47.5-55 \mathrm{~km}$ altitude range. This yields 93 observations. We determine the ratio of the specific potential energy in the upper altitude range to the lower altitude range and find values between 0.4 and 6.9. The average ratio is 2.0 based on the average of the specific energies at each altitude corresponding to an average growth length of $11.0 \mathrm{~km}$. We plot the growth ratio as a function of the values of the specific potential energy at the lower altitude in Figure 4. In Figure 4, we plot a horizontal dashed line at 2.9 that corresponds to the specific potential energy growth ratio for freely propagating waves that are conserving their energy as they propagate upward. This value is the reciprocal of the ratio of the atmospheric density measured in the upper and lower altitude range by the Rayleigh LiDAR, with a value of 0.34 . From the plot, we see that the waves with the larger ratios have smaller energies. Of the 93 measurements, 24 have a ratio greater than 2.9 , with a mean energy of $1.2 \pm 0.2 \mathrm{~J} / \mathrm{kg}$ and a growth length of $5 \mathrm{~km}$. Sixty nine measurements have a ratio less than 2.9 , with a mean energy of $2.3 \pm 0.2 \mathrm{~J} / \mathrm{kg}$ and a growth length of $16 \mathrm{~km}$. This indicates that while some waves grow with altitude, overall, the gravity waves experience saturation where the smaller (larger) amplitude waves grow more (less) rapidly with altitude. Using the ratio of the densities measured by the Rayleigh LiDAR, we determine the ratio of the potential energy densities and find values between 0.2 and 2.5 with an average ratio of 0.68 based on the average of the energy densities at each altitude. This suggests an average decay length of $19 \mathrm{~km}$. When we separate the 
observations by season, we find that the decay lengths are shortest in winter (DJF, 55 observations) with a value of $16 \mathrm{~km}$, values of $25 \mathrm{~km}$ in spring (MAM, 19 observations) and $31 \mathrm{~km}$ in fall (SON, 18 observations). The strongest damping in winter is consistent with the waves having the largest amplitudes in this season. Similar wave damping has been reported in long-term observations from a mid-latitude site in all three seasons [33] and wintertime observations during the recent DEEPWAVE campaign [34].

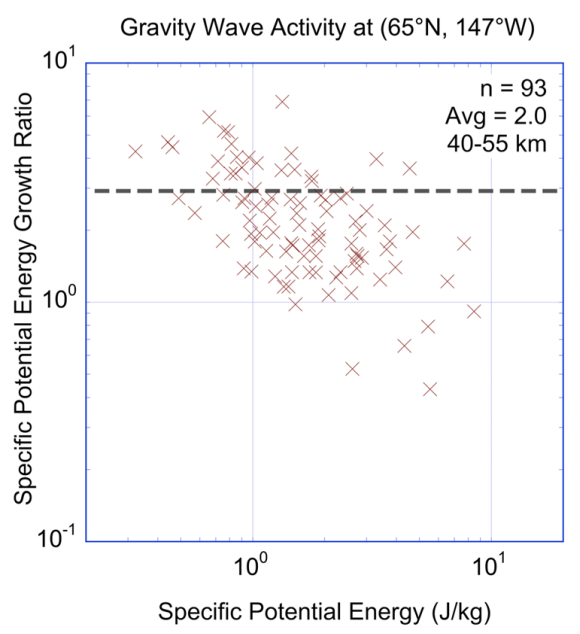

Figure 4. Growth ratio of gravity wave specific potential energy $((47.5-55 \mathrm{~km}) /(40-47.5 \mathrm{~km})$ as a function of specific potential energy $(40.0-47.5 \mathrm{~km})$. The dashed line is plotted at a value of 2.9 and represents the ratio for freely propagating gravity waves that are conserving their energy.

\subsection{The 2009 Stratospheric Sudden Warming}

In the 2008-2009 winter, a major SSW occurred during the third week of January 2009 when the Aleutian High anticyclone and an anticyclone over Europe merged over the pole and split the polar vortex in two. In Figure 5, we see that the evolution of the temperature profile measured at Chatanika reflects the thermal structure of the stratospheric vortex before, during and after the SSW. The temperature profiles show the evolution of the SSW, where before the SSW, the temperature profile has a well-defined stratopause of $277 \mathrm{~K}$ at $58 \mathrm{~km}$ (6 January 2009). The temperature profile then becomes more isothermal with no obvious stratopause (22 January-3 February). Finally, the temperature profile shows the appearance of an elevated stratopause (18-24 February) of $240 \mathrm{~K}$ at $73 \mathrm{~km}$.

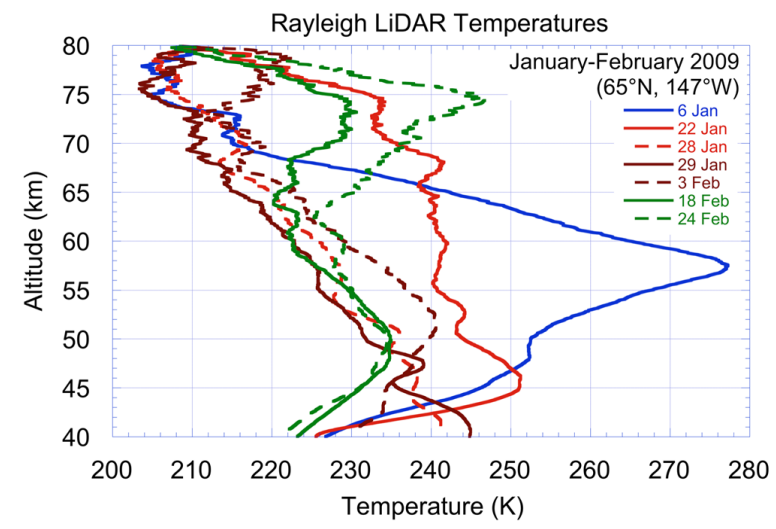

Figure 5. Rayleigh LiDAR temperature profiles for the seven nights of Rayleigh LiDAR data in January-February 2009. The dates are indicated, where "6 Jan" corresponds to the UT day 6 January 2009. 
In Figure 6, we show the 3D evolution of the stratospheric vortex and anticyclones in January and February 2009. The 3D structure was calculated using the United Kingdom Meteorological Office (MetO) global analyses data to calculate the characteristics of the vortices [19,35]. The vortex edge is defined using the stream function-based algorithm [35]. Briefly, the approach involves integrating the strain/rotation parameter $(\mathrm{Q})$ and the horizontal wind speed around stream function isolines in the winter hemisphere. The vortex edge is then defined as the stream function contour associated with the fastest wind speed, provided there is also a change in sign of $\mathrm{Q}$ (such that rotation dominates inside the vortex and shear dominates immediately outside). This methodology is more reliable than a potential vorticity-based approach in the upper stratosphere and lower mesosphere [36]. In Figure 6a, we show the nearly pole-centered, undisturbed polar vortex on 6 January 2009. The vortex first split in the upper stratosphere on 19-20 January and continued to split downward to the mid-stratosphere $(800 \mathrm{~K}, \sim 30 \mathrm{~km}, \sim 10 \mathrm{hPa}$ ) through 22 January (Figure $6 \mathrm{~b})$. The vortex had split downward through the entire stratosphere by 29 January (Figure $6 c$ ). The vortex remained split for almost three weeks until early February when the upper stratospheric vortex recovered. By the second week of February, the upper stratospheric vortex had completely recovered and strengthened, while the middle and lower stratospheric vortex remained weak. This leads to the formation of an elevated stratopause by 24 February 2009 (Figure 6d). The temperature profiles measured at Chatanika reflect the evolution of the vortex and the anticyclones. The LiDAR measurement on 6 January, characterized by the well-defined stratopause, sampled the edge of the vortex. The LiDAR measurements in late January and early February, characterized by the isothermal temperature profiles, sampled the Aleutian anticyclone. The LiDAR measurement later in February, characterized by the elevated stratopause, sampled the interior of the vortex.

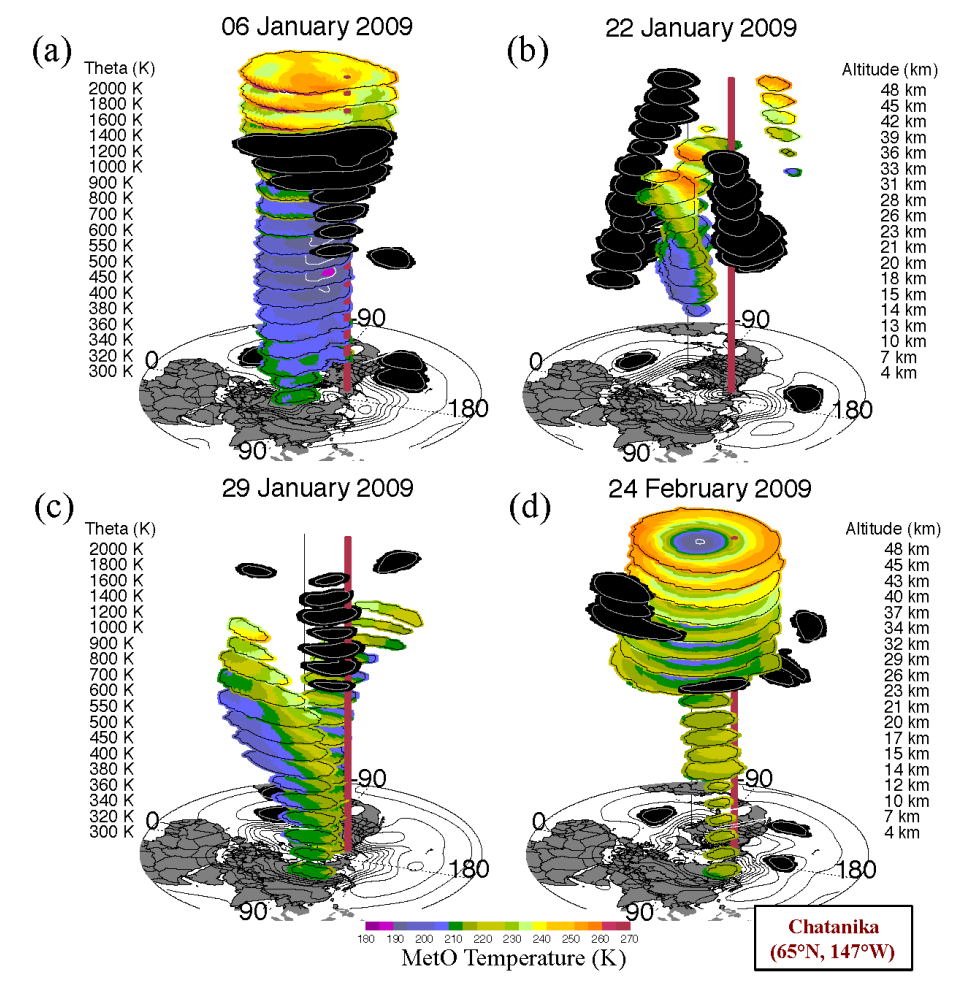

Figure 6. 3D structure of the stratospheric vortex and anticyclones plotted for four days in January-February 2009. The altitude is given in terms of potential temperature, theta, on the left and corresponding altitude on the right. (a) The vortex and anticyclone(s) before an SSW; (b) the vortex and anticyclone(s) at the beginning of the SSW; (c) the vortex and anticyclone(s) a week later; (d) the vortex and anticyclone(s) after the reformation of the vortex. The red vertical line marks the location of Poker Flat Research Range (PFRR), Chatanika, Alaska. 
We show the evolution of the upper tropospheric and mid-stratospheric winds over the Northern Hemisphere in Figure 7 at $300 \mathrm{hPa}(\sim 9 \mathrm{~km})$ and $10 \mathrm{hPa}(\sim 31 \mathrm{~km})$ corresponding to the same four nights as Figure 6 . These altitudes correspond to the peak altitudes of the tropospheric polar front jet and the stratospheric polar night jet. The lower altitude winds (Figure 7a) show the presence (and complexity) of the polar front jet on all four nights. The higher altitude winds (Figure $7 \mathrm{~b}$ ) show the evolution of the polar night jet during an SSW where the polar vortex splits. On 6 January 2009, there is a strong upper level jet that splits on 22 January 2009. The jet remains split and weakened on 29 January 2009. Finally, the polar night jet has disappeared on 24 February.

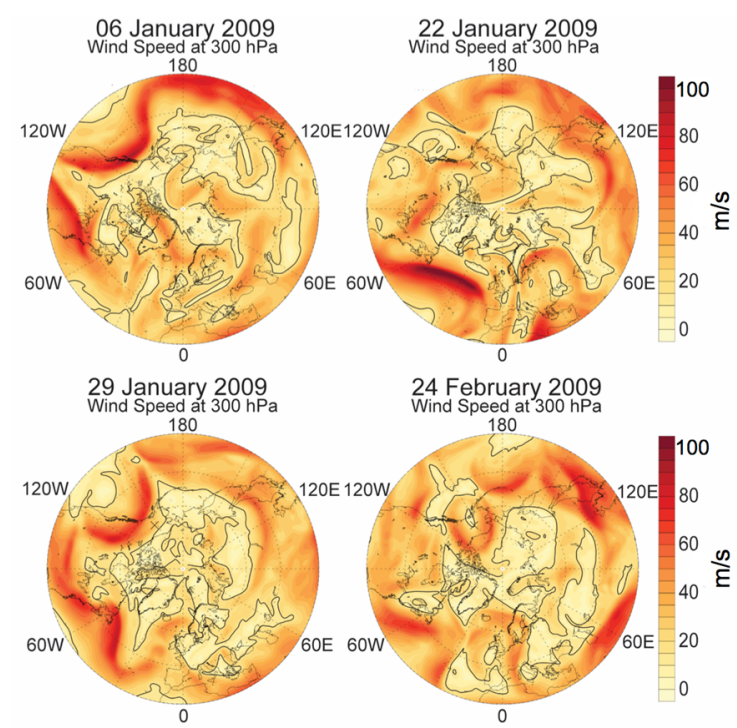

(a)

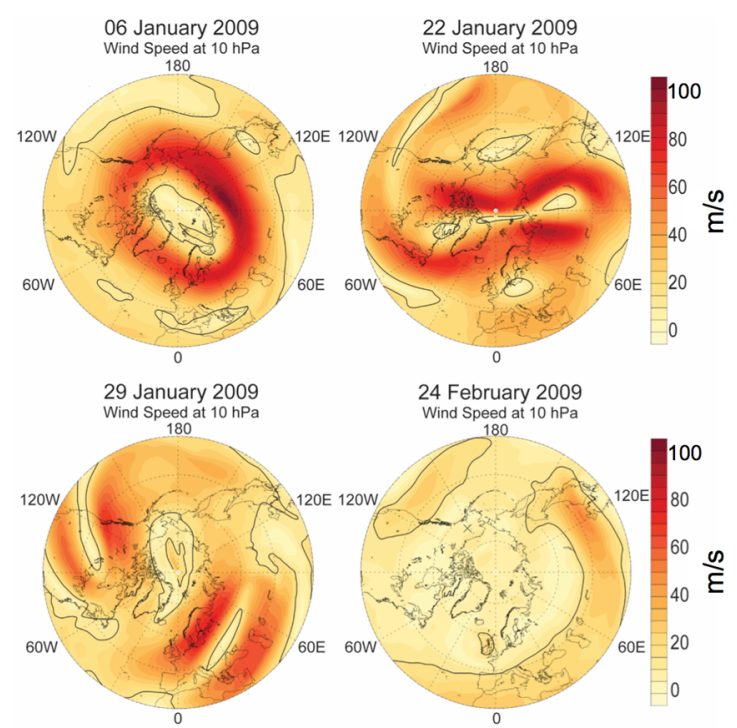

(b)

Figure 7. MERRA horizontal wind speed plotted in false color for four days in January and February 2009 at (a) $300 \mathrm{hPa}(\sim 9 \mathrm{~km})$ and (b) $10 \mathrm{hPa}(\sim 31 \mathrm{~km})$. The solid line is the $15 \mathrm{~m} / \mathrm{s}$ contour.

We show the imbalance in the flow over the Northern Hemisphere in Figure 8. Figure 8a shows $\triangle N B E$ at $300 \mathrm{hPa}(\sim 9 \mathrm{~km})$ and Figure $8 \mathrm{~b}$ shows the $\triangle N B E$ at $10 \mathrm{hPa}(\sim 31 \mathrm{~km})$. We plot the contour value of $\triangle N B E$ of $0.4 \times 10^{-8} \mathrm{~s}^{-2}$ as this value is expected to be a threshold for gravity wave generation [9]. At both altitudes, the distribution of $\triangle N B E$ clearly follows the wind field with regions of higher values of $\triangle N B E$ corresponding to regions of higher horizontal wind speed and shear. However, in the upper troposphere, we see persistent imbalance at the mesoscale across the hemisphere, while in the middle stratosphere, the imbalance is associated with larger features. This is consistent with the fact that we expect more complexity (with frontal activity and flow imbalance) associated with the tropospheric polar front jet than the stratospheric polar night jet.

We plot maps of $\triangle N B E$ again in Figure 9, but we now consider the impact of low wind speeds in filtering the upward propagation of gravity waves. We consider the wind profile between the given altitude and $50 \mathrm{~km}$ and leave those areas blank where the wind speed falls below $15 \mathrm{~m} / \mathrm{s}$ in the column. We show only those regions where gravity waves generated by unbalanced flows with higher horizontal phase speeds are expected to propagate upward to the USLM. Thus, we call this the unfiltered $\triangle N B E$. At both altitudes, we see that the size of the regions where waves generated by unbalanced flow can propagate is steadily reduced as the winds weaken between early January and late February. However, the winds are generally stronger at higher altitudes, and so, the area where waves are generated and can propagate is larger at these altitudes. 


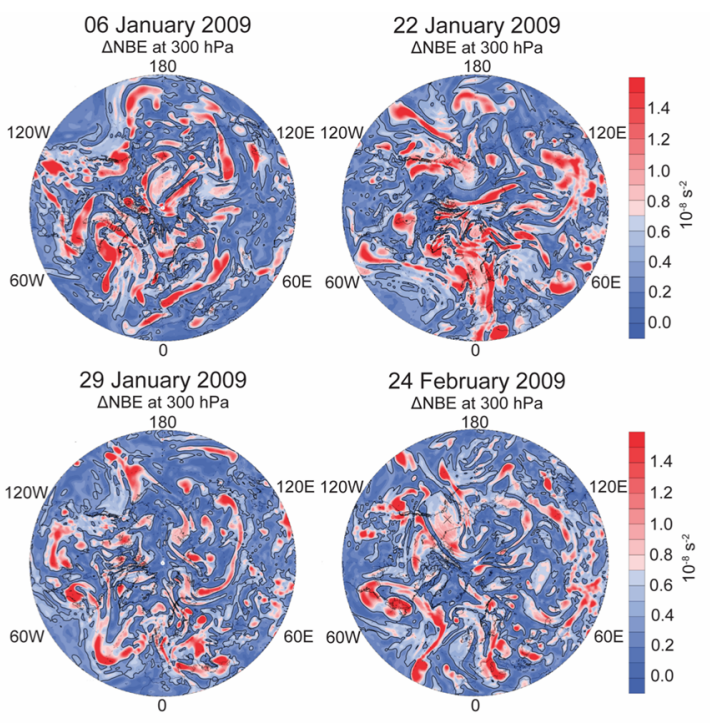

(a)

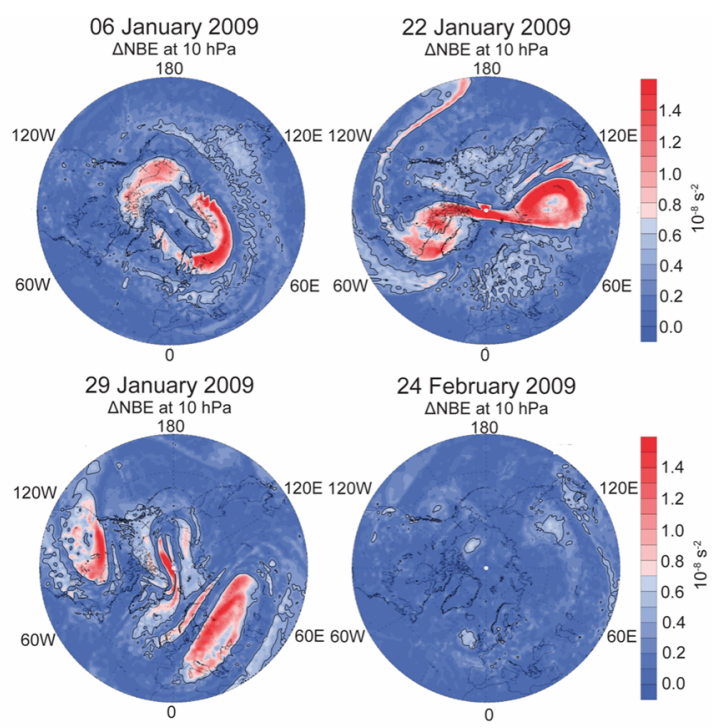

(b)

Figure 8. MERRA nonlinear balance equation $(\triangle N B E)$ plotted in false color for four days in January and February 2009 at (a) $300 \mathrm{hPa}(\sim 9 \mathrm{~km})$ and (b) $10 \mathrm{hPa}(\sim 31 \mathrm{~km})$. The solid line is the $0.4 \times 10^{-8} \mathrm{~s}^{-2}$ contour.

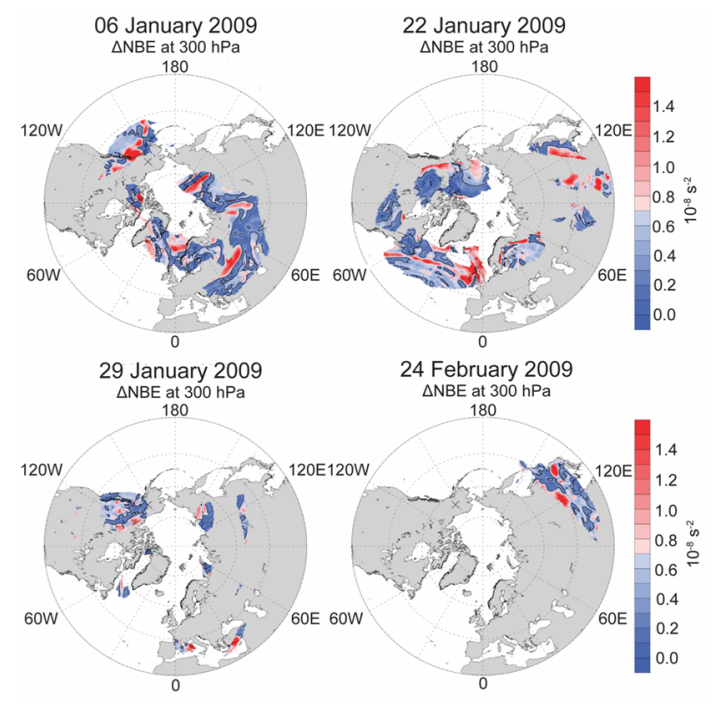

(a)

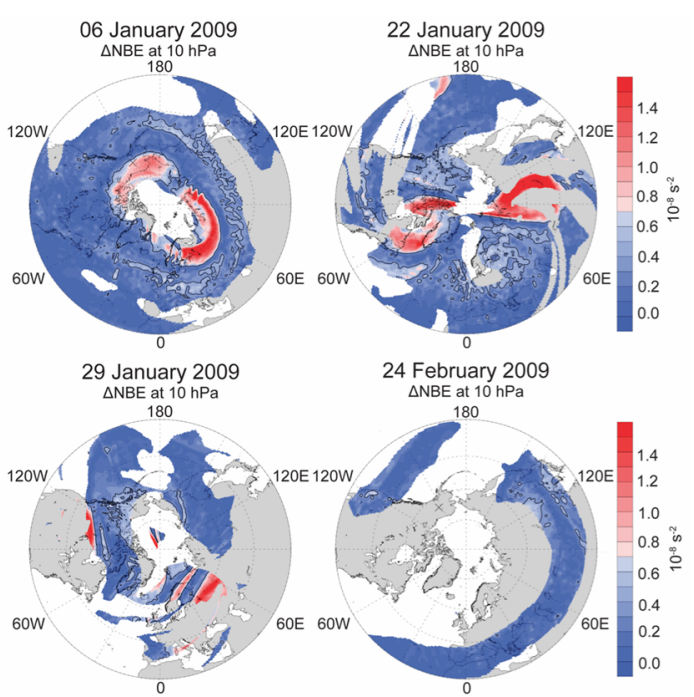

(b)

Figure 9. MERRA unfiltered $\triangle N B E$ plotted in false color for four days in January and February 2009 at (a) $300 \mathrm{hPa}(\sim 9 \mathrm{~km})$ and (b) $10 \mathrm{hPa}(\sim 31 \mathrm{~km})$. The solid line is the $0.4 \times 10^{-8} \mathrm{~s}^{-2}$ contour.

The local winds at Chatanika, like the temperatures, also reflect the evolution of the SSW. In Figure 10 we plot the MERRA wind profiles for the seven nights corresponding to the nights in Figure 5. The wind profiles show the general weakening in stratospheric winds over the course of the SSW. We give both the local wind profiles above Chatanika (Figure 10a) and the RMS winds over a circle of radius $800 \mathrm{~km}$ around Chatanika (Figure 10b). The local wind profiles show more variability, but the same general behavior as the RMS winds. The RMS wind profiles more clearly show the persistent presence of the polar front jet in the upper troposphere at $300 \mathrm{hPa}$ and the progressive disappearance of the stratospheric polar night jet during the course of the SSW. 
(a)

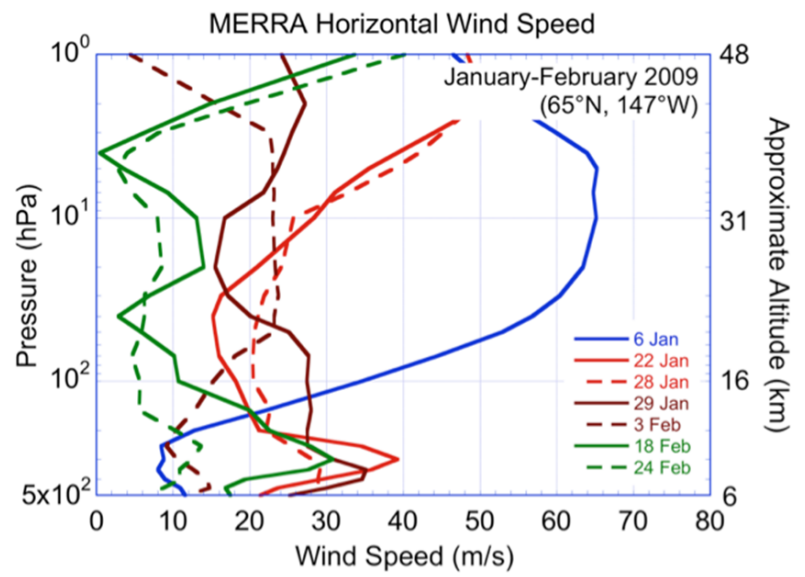

(b)

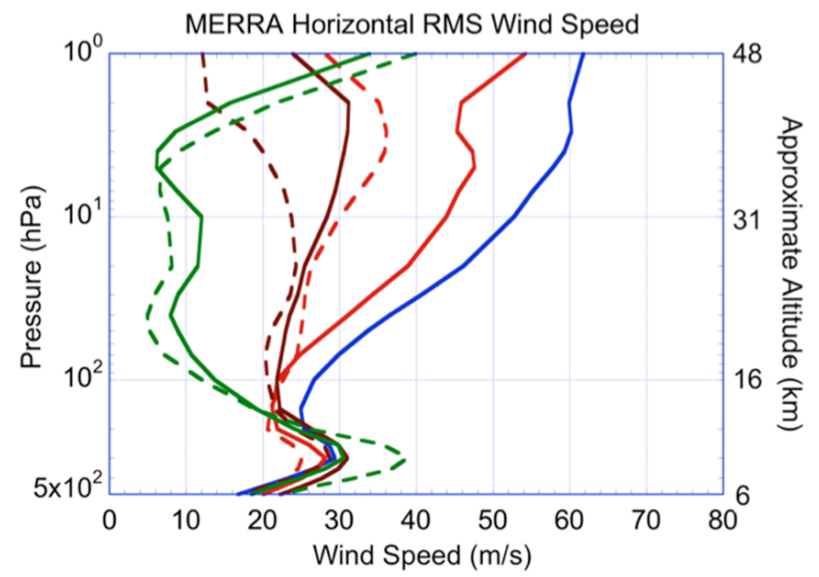

Figure 10. MERRA wind profiles for the seven nights plotted in Figure 5. The dates are indicated where "6 Jan" corresponds to corresponds to the UT day 6 January 2009. (a) Winds over Chatanika; (b) RMS winds speed over an $800 \mathrm{~km}$ in radius circle centered at Chatanika.

We plot the profiles of the areal averaged magnitude of $\triangle N B E$ in Figure 11. We calculate the regional areal average poleward of $50^{\circ} \mathrm{N}$, and the local areal average over a circle of a radius of $800 \mathrm{~km}$ of Chatanika. We show the areal average of the regional and local total $\triangle N B E$ (Figure 8) in Figure 11a,b, respectively. We show the areal average of the regional and local unfiltered $\triangle N B E$ (Figure 9) in Figure 11c,d, respectively. We see the largest values of $\triangle N B E$ associated with the polar night jet in the upper troposphere. In the stratosphere, the values of $\triangle N B E$ generally decrease over the two-month period. The values of the locally-averaged $\triangle N B E$ is generally higher than the regionally-averaged values, which reflects the location of Alaska relative to the tropospheric and stratospheric jets and the wind shears associated with the presence of the polar vortex and the anticyclone. The behavior of $\triangle N B E$ is consistent with the evolution of the wind field, where the unbalanced flow decreases as the jets weaken. However, the decrease in the unfiltered $\triangle N B E$ is significantly greater than the decrease in the total $\triangle N B E$. 
(a)

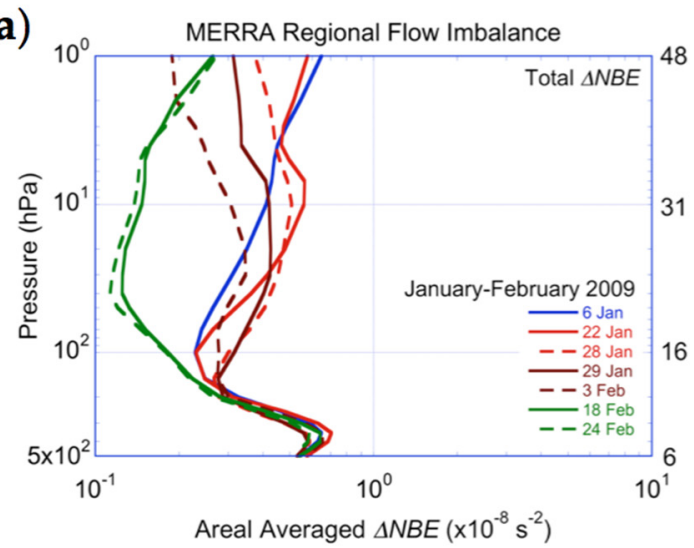

(c)

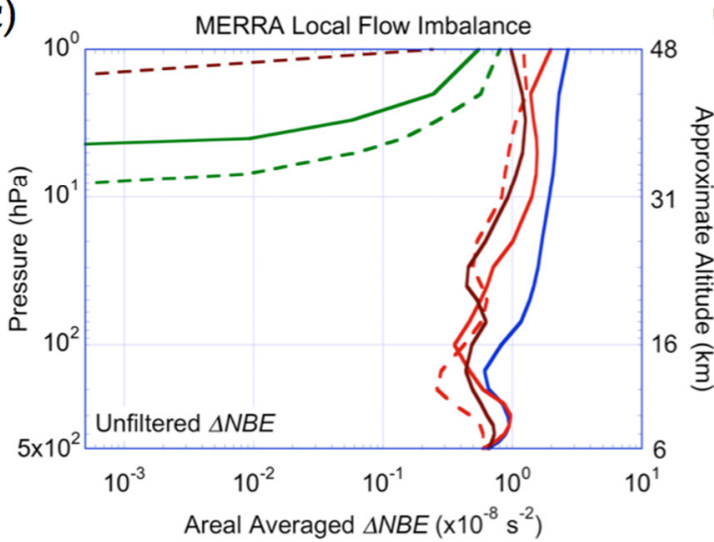

(b)

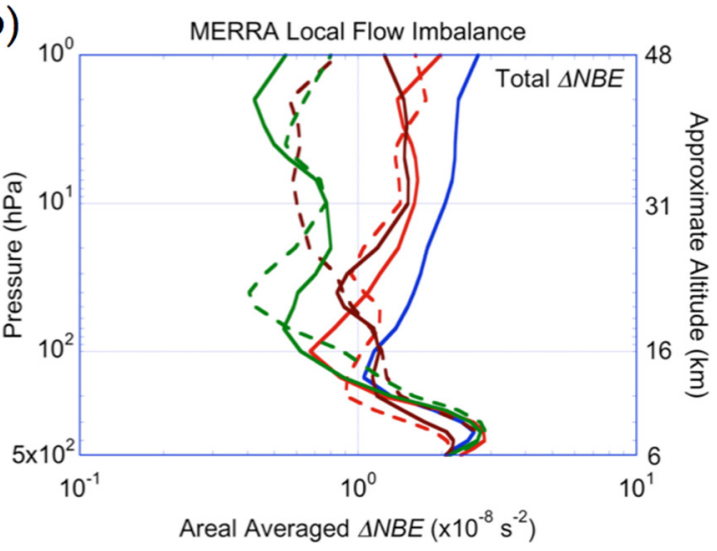

(d)

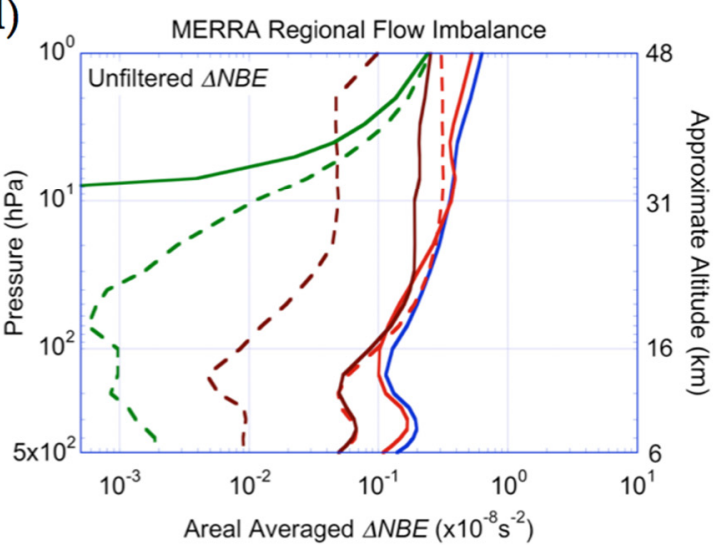

Figure 11. MERRA-derived $\triangle N B E$ profiles for the seven nights in Figure 5. (a) Areal average of total $\triangle \mathrm{NBE}$ poleward of $50^{\circ} \mathrm{N} ;($ b) areal average of total $\triangle N B E$ over the $800 \mathrm{~km}$ in radius circle centered on Chatanika; (c) areal average of unfiltered $\triangle N B E$ poleward of $50^{\circ} \mathrm{N} ;(\mathbf{d})$ areal average of unfiltered $\triangle N B E$ over the $800 \mathrm{~km}$ in radius circle centered on Chatanika.

We plot the gravity wave activity measured at Chatanika during this period in Figure 12. In Figure 12a, we show the gravity wave activity and the wind speed over Chatanika at $300 \mathrm{hPa}$ and $10 \mathrm{hPa}$. In Figure 12b, we show the gravity wave activity and the unfiltered regional $\triangle N B E$ at $300 \mathrm{hPa}$ and the unfiltered local $\triangle N B E$ at $10 \mathrm{hPa}$. The gravity waves have the largest specific potential energies in early January, and the energy of the waves generally decreases in late January and February. The variation in gravity wave activity follows the variation in wind speed at $10 \mathrm{hPa}$. There is a general decrease in both gravity wave activity and wind speed over the seven-week period that has also been reported in satellite studies of stratospheric gravity wave activity during the 2009 SSW [37]. The decrease in gravity wave activity on 29 January followed by an increase on 3 February corresponds to a decrease in wind speed followed by an increase in wind speed. The variation of gravity wave activity over the seven-week period shows a significantly higher correlation with the unfiltered $\triangle N B E$ than the total $\triangle N B E$. There is also a general decrease in both regional and local $\triangle N B E$ over the seven-week period. After 29 January, there is no unfiltered $\triangle N B E$ within $800 \mathrm{~km}$ of Chatanika, and we do not plot any values for the local unfiltered $\triangle N B E$. Strong winds can both generate gravity waves and also allow gravity waves to propagate. The largest gravity wave energies are found when both winds are strongest, and the flow imbalance is greatest on 6 January. The lowest wave energies are found when the winds are weakest, and the flow imbalance is least on 18 February and 24 February. 

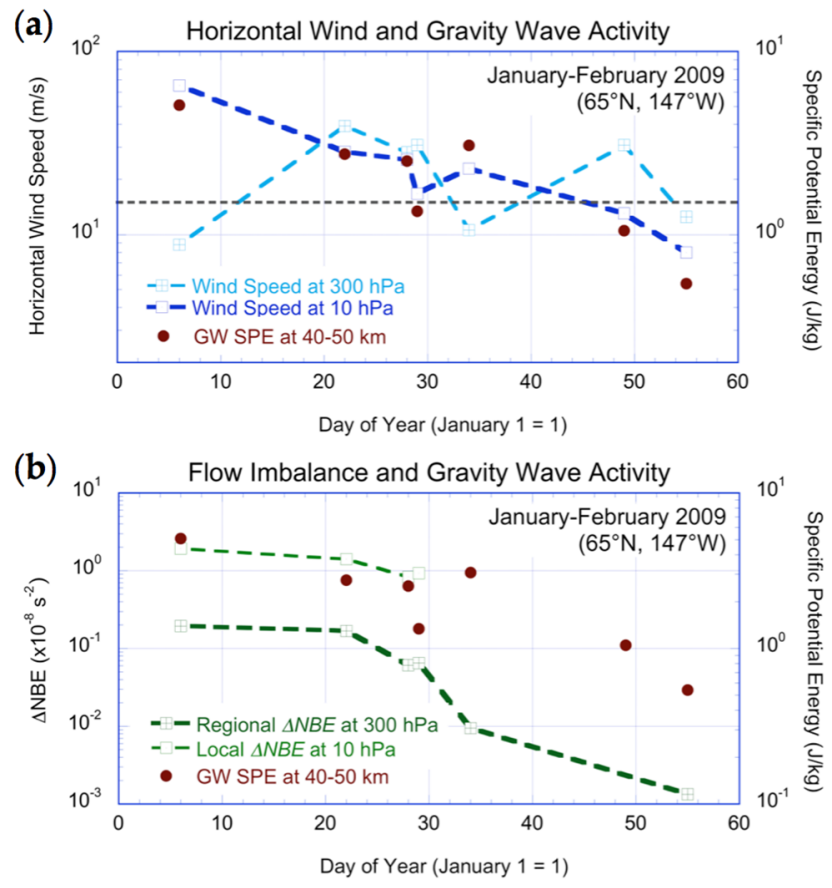

Figure 12. (a) Specific potential energy (SPE) and horizontal wind speed in January-February 2009 for the day of year; (b) SPE and ageostrophy plotted in January-February 2009 as the day of year. The day of year counts from 1 on 1 January and day of year 30 corresponds to 30 January. Regional $\triangle N B E$ represents the areal average poleward of $50^{\circ} \mathrm{N}$. Local $\triangle N B E$ represents the areal average over the $800-\mathrm{km}$ circle centered on Chatanika.

\subsection{Correlation between Gravity Wave Activity and Winds and Ageostrophy}

To investigate the relationship between winds and the gravity wave activity at Chatanika, we calculate the correlation between the potential energy density of the gravity waves at $40-50 \mathrm{~km}$ and the horizontal wind speeds over Chatanika at each of the 26 altitudes. We present the Spearman correlation coefficients as a function of altitude in Figure 13. We consider the correlation in four distinct ways; all 152 observations ("All"), 81 observations from December, January, and February ("DJF"), 65 observations from DJF when the winter was disturbed ("DJF-DW") and 16 observations from DJF when the winter was quiet ("DJF-QW"). Of the 13 winters, 11 are disturbed and two are quiet [8]. Over all of the 152 observations, the correlation coefficient is greater than 0.6 between $20 \mathrm{hPa}(\sim 26 \mathrm{~km})$ and $5 \mathrm{hPa}(\sim 36 \mathrm{~km})$ with a maximum value of 0.7 at $10 \mathrm{hPa}(\sim 31 \mathrm{~km})$. The correlation coefficients increase when we only consider the wintertime gravity wave activity, and the correlation coefficient is greater than 0.6 between $40 \mathrm{hPa}(\sim 22 \mathrm{~km})$ and $3 \mathrm{hPa}(\sim 40 \mathrm{~km})$ with a maximum value of 0.8 at $10 \mathrm{hPa}(\sim 31 \mathrm{~km})$. The altitude distribution changes significantly between disturbed and quiet winters. During disturbed winters, the altitude distribution is similar to the distribution during all observations, with a maximum value of 0.7 at $10 \mathrm{hPa}(\sim 31 \mathrm{~km})$, while during quiet winters, the correlation moves downward having a maximum value of 0.8 at $70 \mathrm{hPa}(\sim 18 \mathrm{~km})$. The Pearson correlation coefficients show similar variation in altitude. This correlation analysis yields a positive correlation indicating that the gravity wave potential energies increase with wind speed at all altitudes. The analysis of disturbed and quiet winters shows that the highest correlation are found at the altitudes where the winds are weakest and indicates that the wind controls the propagation of gravity waves by low winds filtering the upward propagation of waves in the lower stratosphere. 


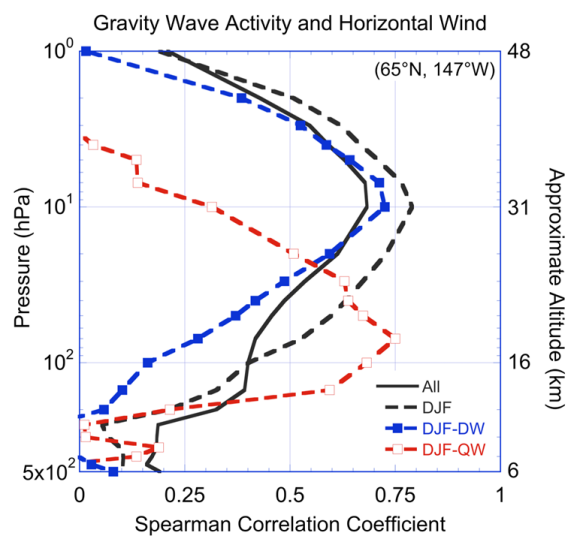

Figure 13. Spearman correlations of gravity wave-specific potential energy and horizontal wind speed in altitude at Chatanika. "All" represents all 152 nights. "DJF" represents all winter nights (December, January, February). "DJF-DW" represents all winter nights in disturbed winters. "DJF-QW" is all winter nights in quiet winters.

The difference between the correlation in disturbed and quiet winters reflects the change in the structure of the middle atmosphere winds. During quiet winters, the winds in the middle atmosphere increase steadily with altitude in the stratosphere, while during disturbed winters, the winds are weaker in the stratosphere, and a zero wind line moves down through the stratosphere and blocks the propagation of low phase speed gravity waves (e.g., $[18,19])$. The wintertime correlation between the gravity wave activity and the stratospheric winds is also evident in successive Arctic winters. We show the mean wintertime gravity wave activity as a function of year in Figure 14a. There was only one LiDAR observation made in the winter of 1999-2000 and the winter of 2000-2001, while there were between four and 11 observations made in the other 11 winters. The specific potential energies vary by a factor of six between $1 \mathrm{~J} / \mathrm{kg}$ and $6 \mathrm{~J} / \mathrm{kg}$. We show the seasonal median wind profile over the 13 winter seasons in Figure 14b. The median wind profiles also show significant variability with strong winds during quiet winters (e.g., 2004-2005, 2010-2011) and weak winds during strongly disturbed winters (e.g., 2001-2002, 2003-2004). The gravity wave activity is highest during the quiet winters of 2004-2005 and 2010-2011 (4-6 J/ kg) and lowest in the disturbed winters of 2001-2002 and 2003-2004 $(1 \mathrm{~J} / \mathrm{kg})$. The winter of 2003-2004 was highly disturbed due to the occurrence of a major and persistent SSW and the formation of an elevated stratopause, while the winter of 2004-2005 was undisturbed with a robust polar vortex $[8,18]$.

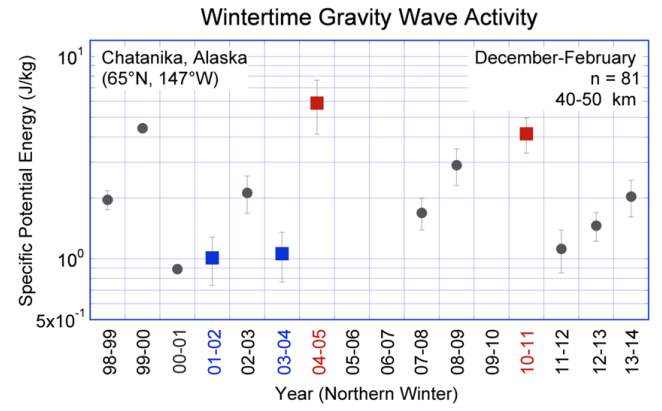

(a)

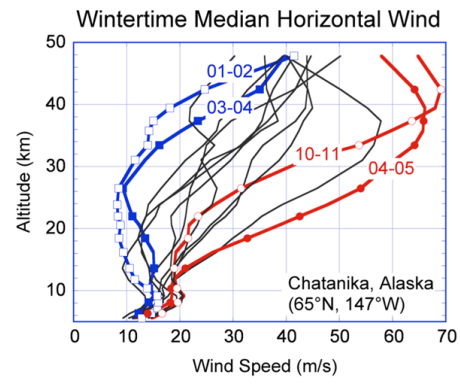

(b)

Figure 14. (a) Wintertime averaged values of specific potential energy plotted as a function of year. Values for 2005-2006, 2006-2007 and 2009-2010 are omitted because no LiDAR measurements were made during those winters. (b) Wintertime median horizontal wind speed over Poker Flat Research Range. Disturbed winters with low wind speeds are plotted in blue. Quiet winters with high wind speeds are plotted in red. The corresponding gravity wave energies are also plotted in blue and red. 
To understand the relationship between unbalanced flows and the gravity wave activity at Chatanika, we calculate the correlation between the potential energy density of the gravity waves at $40-50 \mathrm{~km}$ and the $\triangle N B E$ at each of the 26 altitudes. We present the Spearman correlation coefficients as a function of altitude in Figure 15. While the values of the correlation coefficients are generally low, some patterns are evident. The correlations with the unfiltered $\triangle N B E$ are higher than with the total $\triangle N B E$, indicating that the role of the spontaneous adjustment of unbalanced flows as a source of gravity waves is highly modulated by wind filtering. Furthermore, we see that the gravity wave activity is more highly correlated with the local flow imbalance at higher altitudes and more highly correlated with the regional flow imbalance at lower altitudes. This is consistent with the fact that inertia-gravity waves propagate upward at relatively shallow angles, and so, low altitude sources should be further away than high altitude sources. The higher correlation with local unfiltered $\triangle N B E$ in the upper stratosphere may indicate that spontaneous adjustment of unbalanced flows acts as a local source of the gravity waves that are growing with altitude (Figure 4).

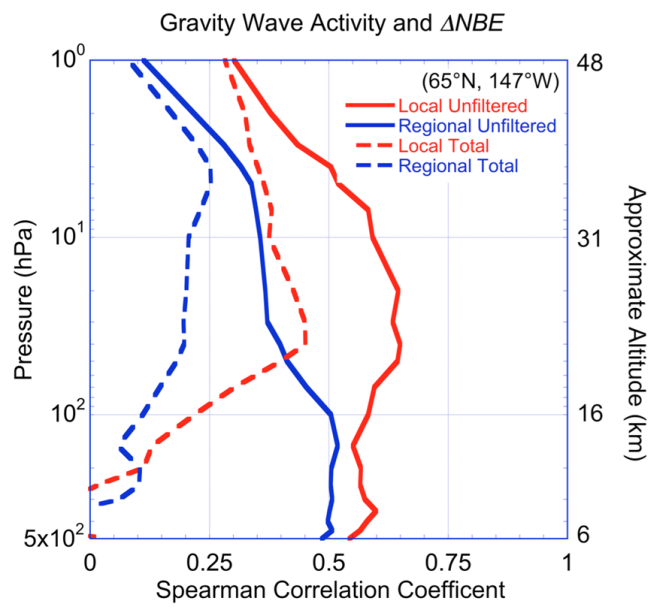

Figure 15. Spearman correlation of gravity wave-specific potential energy and $\triangle N B E$ in altitude at Chatanika. "Local unfiltered" represents the correlation with $\triangle N B E$ averaged over all of the area within $800 \mathrm{~km}$ of Chatanika with winds greater than $15 \mathrm{~m} / \mathrm{s}$ (red solid). "Regional unfiltered" represents the correlation with $\triangle N B E$ averaged over all of the area poleward of $50^{\circ} \mathrm{N}$ with winds greater than $15 \mathrm{~m} / \mathrm{s}$ (blue solid). "Local total" represents the correlation with $\triangle N B E$ averaged over all of the area within $800 \mathrm{~km}$ of Chatanika (red dashed). "Regional total" represents the correlation with $\triangle N B E$ averaged over all of the area poleward of $50^{\circ} \mathrm{N}$ (blue dashed).

\section{Discussion}

The USLM gravity wave activity at Chatanika has a similar daily variability and seasonal variation with the winter maximum as observed with Rayleigh LiDAR at a variety of mid-latitude and high-latitude sites (e.g., [33,34,38-41]). Furthermore, the gravity waves at Chatanika, like these other sites, appear to be saturated with lower amplitude waves growing more rapidly with altitude than the larger amplitude waves. The modulation of gravity wave propagation by stratospheric winds and critical layer filtering has been documented since the 1990s [41]. Several studies in the Arctic have highlighted this modulation of gravity wave activity by the winds $[18,37,42]$. In this study, we have shown the systematic interannual modulation of the wintertime gravity wave activity associated with the occurrence of SSWs.

We have investigated the influence of winds and spontaneous adjustment of unbalanced flows on gravity wave activity. Three recent investigations of unbalanced flow and gravity wave generation have focused on case studies in the Antarctic and in the Arctic [9,16,17]. An investigation that combined high-resolution radiosonde measurements of gravity waves in the lower stratosphere $(\sim 20-30 \mathrm{~km})$ with a wave-resolved global circulation model suggested that inertia-gravity waves were generated by 
a spontaneous adjustment of the ageostrophic Polar Night Jet over Antarctica [16]. An investigation of the 2008 Arctic SSW combined satellite measurements of averaged gravity wave activity $(\sim 20-25 \mathrm{~km})$ with reanalysis-based estimates of $\triangle N B E$ associated with the Polar Front Jet at $350 \mathrm{hPa}$ showed that the wave activity and unbalanced flow were correlated, but that there was not a clear one-to-one correlation between peaks in the wave activity and peaks in $\triangle N B E$ [17]. An investigation of the 2009 Arctic SSW combined mesoscale simulations, reanalysis and satellite observations and showed the generation of gravity wave packets in the upper stratosphere $(\sim 40-50 \mathrm{~km})$ associated with unbalanced flows and $\triangle N B E$ in the mid-stratosphere $(\sim 30 \mathrm{~km})$ [9]. In all three studies, the authors note that one of the major challenges in separating the relative roles of spontaneous adjustment and wind in determining the origin of gravity waves is that regions of strong winds both support generation and propagation of gravity waves controlling the gravity wave activity. This ambiguity has long been recognized as fundamental in studies of gravity wave activity [43]. Our investigation shows that while the gravity wave activity is correlated with ageostrophy the correlation is only evident when the effects of wind on gravity wave propagation are included in the analysis.

We have not directly investigated orographic sources of gravity waves in this study. We expect that the topography of Alaska with the Alaska and Brookes Ranges give rise to gravity waves. Global satellite studies have revealed hotspots of stratospheric gravity wave activity over orographic features and attributed the waves to orographic forcing by the underlying topography (e.g., [32,44]). Longitudinal asymmetries in the observed wave variances revealed strong wave sources over Alaska in January 2005 [44]. However, Rayleigh LiDAR observations at Chatanika and Kangerlussuaq, Greenland, have shown that during the 2008 and 2009 SSWs with similar wind regimes at both sites, the gravity wave activity at Chatanika was lower, suggesting weaker sources of gravity waves at Chatanika than Kangerlussuaq [19].

\section{Conclusions}

We have documented the USLM gravity wave activity $(40-50 \mathrm{~km})$ over 14 years based on uniform processing of a high-quality set of Rayleigh LiDAR observations. Despite large daily variability, the gravity wave activity shows a clear annual cycle with a maximum in winter and systematic inter-annual variability associated with stratospheric sudden warming events. The gravity waves appear saturated with the larger amplitude waves decaying more rapidly with altitude than the lower amplitude waves. Overall, the waves have a decay length of $19 \mathrm{~km}$, with the greatest decay in wintertime.

We find that the USLM gravity wave activity is controlled by the winds in the lower stratosphere, where weak winds in the lower stratosphere block the upward propagation of inertia-gravity waves through critical layer filtering. This control is evident on both daily and seasonal time scales, where systematic changes in the winds are associated with SSWs. We also find that the gravity wave activity is correlated with flow imbalance after wind-filtering effects are included. Thus, we conclude that the primary control of the gravity wave activity is critical layer filtering by the winds in the lower stratosphere, and the secondary control of gravity wave activity is spontaneous adjustment of unbalanced flow associated with the tropospheric and stratospheric jets.

Acknowledgments: The authors acknowledge the staff at Poker Flat Research Range for their ongoing support of the LiDAR program. The authors acknowledge the assistance of the following individuals in making the ongoing LiDAR observations while students at the University of Alaska Fairbanks: J. Breese, L. J. Cutler, B. K. Irving, Z. Krehlik, J. Li, A. S. Light, C. M. Martus, S. Nadakuditi, M. A. Peshave, S. Robinson, T. E. Stern, L. Su, B. Thurairajah, W. Wang, R. Wing, and J. Yue. The authors acknowledge support for this research by the United States National Science Foundation under Grants PLR 1314323, AGS 1343056, PLR 1107498 and PLR 0632387 and the Alaska Project of the Japanese National Institute of Information and Communications Technology.

Author Contributions: Colin C. Triplett and Richard L. Collins analyzed the LiDAR and MERRA data. Richard L. Collins, V. Lynn Harvey, Kohei Mizutani and Kim Nielsen conceived of and designed the Rayleigh LiDAR experiments. V. Lynn Harvey analyzed the polar vortex and anticyclones. Colin C. Triplett, Richard L. Collins and V. Lynn Harvey wrote the paper. All of the authors reviewed the paper.

Conflicts of Interest: The authors declare no conflict of interest. 


\section{References}

1. Houghton, J.T. The stratosphere and mesosphere. Q. J. R. Meteorol. Soc. 1978, 104, 1-29. [CrossRef]

2. Plumb, R.A.; Vincent, R.A. Introduction to special issue on middle atmosphere. Pure Appl. Geophys. 1989, 130, 149-150. [CrossRef]

3. Fritts, D.C.; Alexander, M.J. Gravity wave dynamics and effects in the middle atmosphere. Rev. Geophys. 2003, 41, 1003. [CrossRef]

4. Alexander, M.J.; Sato, K. Gravity wave dynamics and climate: An update from the SPARC gravity wave activity. SPARC Newsl. 2015, 44, 9-13.

5. Fritts, D.C.; Smith, R.B.; Taylor, M.J.; Doyle, J.D.; Eckermann, S.D.; Dörnbrack, A.; Rapp, M.; Williams, B.P.; Pautet, P.-D.; Bossert, K.; et al. The Deep Propagating Gravity Wave Experiment (DEEPWAVE): An Airborne and Ground-Based Exploration of Gravity Wave Propagation and Effects from Their Sources throughout the Lower and Middle Atmosphere. Bull. Am. Meteorol. Soc. 2016, 97, 425-453. [CrossRef]

6. Chandran, A.; Collins, R.L.; Garcia, R.R.; Marsh, D.R. A case study of an elevated stratopause generated in the Whole Atmosphere Community Climate Model. Geophys. Res. Lett. 2011, 38, L08804. [CrossRef]

7. Chandran, A.; Collins, R.L.; Garcia, R.R.; Marsh, D.R.; Harvey, V.L.; Yue, J.; de la Torre, J. A climatology of elevated stratopause events in the whole atmosphere community climate model. J. Geophys. Res. 2013, 118, 1234-1246. [CrossRef]

8. Chandran, A.; Collins, R.L.; Harvey, V.L. Stratosphere-mesosphere coupling during stratospheric sudden warming events. Adv. Space Res. 2014, 53, 1265-1289. [CrossRef]

9. Limpasuvan, V.; Alexander, M.J.; Orsolini, Y.J.; Wu, D.L.; Richter, J.H.; Yamashita, C. Mesoscale simulation of gravity waves during the 2008-2009 major stratospheric sudden warming. J. Geophys. Res. 2011, 116, D17104. [CrossRef]

10. Ren, S.; Polavarapu, S.; Beagley, S.R.; Nezlin, Y.; Rochon, Y.J. The impact of gravity wave drag mesospheric analyses of the 2006 stratospheric major warming. J. Geophys. Res. 2011, 116, D19116. [CrossRef]

11. Rossby, C.G. On the mutual adjustment of pressure and velocity distributions in certain simple current systems. II. J. Mar. Res. 1938, 7, 239-263. [CrossRef]

12. Cahn, A. An investigation of the free oscillations of a simple current system. J. Atmos. Sci. 1945, 2, 113-119. [CrossRef]

13. Obukhov, A. On the question of geostrophic wind (in Russian). Bull. USSR Acad. Sci. Geograph. Geophys. Ser. 1949, 13, 281-306.

14. Plougonven, R.; Zhang, F. Internal gravity waves from atmospheric jets and fronts. Rev. Geophys. 2014, 52, 33-76. [CrossRef]

15. Fritts, D.C.; Luo, Z. Gravity wave excitation by geostrophic adjustment of the jet stream, part I, Two-dimensional forcing. J. Atmos. Sci. 1992, 49, 681-697. [CrossRef]

16. Sato, K.; Yoshiki, M. Gravity wave generation around the polar vortex in the stratosphere revealed by 3-hourly radiosonde observations at Syowa Station. J. Atmos. Sci. 2008, 65, 3719-3735. [CrossRef]

17. Wang, L.; Alexander, M.J. Gravity wave activity during stratospheric sudden warmings in the 2007-2008 Northern Hemisphere winter. J. Geophys. Res. 2009, 114, D18108. [CrossRef]

18. Thurairajah, B.; Collins, R.L.; Harvey, V.L.; Lieberman, R.S.; Mizutani, K. Rayleigh lidar observations of reduced gravity wave activity during the formation of an elevated stratopause in 2004 at Chatanika, Alaska $\left(65^{\circ} \mathrm{N}, 147^{\circ} \mathrm{W}\right)$. J. Geophys. Res. 2010, 115, D13109. [CrossRef]

19. Thurairajah, B.; Collins, R.L.; Harvey, V.L.; Lieberman, R.S.; Gerding, M.; Mizutani, K.; Livingston, J.M. Gravity wave activity in the Arctic stratosphere and mesosphere during the 2007-2008 and 2008-2009 stratospheric sudden warming events. J. Geophys. Res. 2010, 115, D00N06. [CrossRef]

20. Collins, R.L.; Lehmacher, G.A.; Larsen, M.F.; Mizutani, K. Estimates of vertical eddy diffusivity in the upper mesosphere in the presence of a mesospheric inversion layer. Ann. Geophys. 2011, 29, 2019-2029. [CrossRef]

21. Irving, B.K.; Collins, R.L.; Lieberman, R.S.; Thurairajah, B.; Mizutani, K. Mesospheric Inversion Layers at Chatanika, Alaska $\left(65^{\circ} \mathrm{N}, 147^{\circ} \mathrm{W}\right)$ : Rayleigh lidar observations and analysis. J. Geophys. Res. Atmos. 2014, 119, 11235-11249. [CrossRef]

22. SPARC intercomparison of middle atmosphere climatologies. Available online: https://ntrs.nasa.gov/ archive/nasa/casi.ntrs.nasa.gov/20030020951.pdf (accessed on 18 January 2017). 
23. Randel, W.; Udelhofen, P.; Fleming, E.; Geller, M.; Gelman, M.; Hamilton, K.; Karoly, D.; Ortland, D.; Pawson, S.; Swinbank, R.; et al. The SPARC intercomparison of middle-atmosphere climatologies. J. Clim. 2004, 17, 986-1003. [CrossRef]

24. Gill, H.E. Atmosphere-Ocean Dynamics; Academic Press Inc.: New York, NY, USA, 1982; p. 662.

25. Rienecker, M.M.; Suarez, M.J.; Gelaro, R.; Todling, R.; Bacmeister, J.; Liu, E.; Bosilovich, M.G.; Schubert, S.D.; Takacs, L.; Kim, G.-K.; et al. MERRA: NASA's Modern-Era Retrospective Analysis for Research and Applications. J. Clim. 2011, 24, 3624-3648. [CrossRef]

26. Champion, K.S.W.; Cole, A.E.; Kantor, A.J. Standard and Reference Atmospheres. In Handbook of Geophysics and the Space Environment; Jursa, A.S., Ed.; Air Force Geophysics Laboratory: Hanscom AFB, MA, USA, 1985; pp. 14:1-14:43.

27. Petterssen, S. On the relation between vorticity, deformation, and divergence and the configuration of the pressure field. Tellus 1953, 5, 231-237. [CrossRef]

28. Zhang, F.; Koch, S.E.; Davis, C.A.; Kaplan, M.L. A survey of unbalanced flow diagnostics and their application. Adv. Atmos. Sci. 2000, 17, 205-218. [CrossRef]

29. Zhang, F.; Koch, S.E.; Davis, C.A.; Kaplan, M.L. Wavelet analysis and the governing dynamics of a large-amplitude mesoscale gravity-wave event along the East Coast of the United States. Q. J. R. Meteorol. Soc. 2001, 127, 2209-2245. [CrossRef]

30. Hertzog, A.; Souprayen, C.; Hauchecorne, A. Observation and backward trajectory of an inertia-gravity wave in the lower stratosphere. Ann. Geophys. 2001, 19, 1141-1155. [CrossRef]

31. Press, W.H.; Teukolsky, S.A.; Vetterling, W.T.; Flannery, B.P. Numerical Recipes in Fortran: The Art of Scientific Computing, 2nd ed.; Cambridge University Press: Cambridge, MA, USA, 1992; pp. 1-963.

32. Hoffmann, L.; Xue, X.; Alexander, M.J. A global view of stratospheric gravity wave hotspots located with Atmospheric Infrared Sounder observations. J. Geophys. Res. Atmos. 2013, 118, 416-434. [CrossRef]

33. Mzé, N.; Hauchecorne, A.; Keckhut, P.; Thétis, M. Vertical distribution of gravity wave potential energy from long-term Rayleigh lidar data at a northern middle-latitude site. J. Geophys. Res. Atmos. 2014, 119, 12069-12083. [CrossRef]

34. Kaifler, B.; Kaifler, M.; Ehard, B.; Dörnbrack, A.; Rapp, M.; Fritts, D.C. Influences of source conditions on mountain wave penetrations into the stratosphere and mesosphere. Geophys. Res. Lett. 2015, 42. [CrossRef]

35. Harvey, V.L.; Pierce, R.B.; Fairlie, T.D.; Hitchman, M.H. A climatology of stratospheric polar vortices and anticyclones. J. Geophys. Res. 2002, 107, 4442. [CrossRef]

36. Harvey, V.L.; Randall, C.E.; Hitchman, M.H. Breakdown of potential vorticity-based equivalent latitude as a vortex-centered coordinate in polar winter mesosphere. J. Geophys. Res. 2009, 114, D22105. [CrossRef]

37. Ern, M.; Trinh, Q.T.; Kaufmann, M.; Krisch, I.; Preusse, P.; Ungermann, J.; Zhu, Y.; Gille, J.C.; Mlynczak, M.G.; Russell, J.M.; et al. Satellite observations of middle atmosphere gravity wave absolute momentum flux and of its vertical gradient during recent stratospheric warming. Atmos. Chem. Phys. 2016, 16, 9983-10019. [CrossRef]

38. Ehard, B.; Achtert, P.; Gumbel, J. Long-term lidar observations of wintertime gravity wave activity over northern Sweden. Ann. Geophys. 2014, 32, 1395-1405. [CrossRef]

39. Rauthe, M.; Gerding, M.; Lübken, F.-J. Seasonal changes in gravity wave activity measured by lidars at mid-latitudes. Atmos. Chem. Phys. 2008, 8, 6775-6787. [CrossRef]

40. Whiteway, J.A.; Carswell, A.I. Lidar observations of gravity wave activity in the upper stratosphere over Toronto. J. Geophys. Res. 1995, 100, 14113-14124. [CrossRef]

41. Wilson, R.; Chanin, M.L.; Hauchecorne, A. Gravity waves in the middle atmosphere observed by Rayleigh lidar 2. Climatology. J. Geophys. Res. 1991, 96, 5169-5183. [CrossRef]

42. Duck, T.J.; Whiteway, J.A.; Carswell, A.I. The gravity wave-arctic stratospheric vortex interaction. J. Atmos. Sci. 2001, 58, 3581-3596. [CrossRef]

43. O'Sullivan, D.; Dunkerton, T.J. Generation of inertia-gravity waves in a simulated life cycle of baroclinic instability. J. Atmos. Sci. 1995, 52, 3695-3716. [CrossRef]

44. Wu, D.L.; Eckermann, S.D. Global gravity wave variances from Aura MLS: Characteristics and interpretation. J. Atmos. Sci. 2008, 65, 3695-3718. [CrossRef]

(C) 2017 by the authors; licensee MDPI, Basel, Switzerland. This article is an open access article distributed under the terms and conditions of the Creative Commons Attribution (CC BY) license (http:/ / creativecommons.org/licenses/by/4.0/). 